\title{
Genetic Variants in Hormone-Related Genes and Risk of Breast Cancer
}

\author{
Tess Clendenen $^{1 *}$, Anne Zeleniuch-Jacquotte ${ }^{1,2}$, Isaac Wirgin ${ }^{3}$, Karen L. Koenig ${ }^{1}$, Yelena Afanasyeva ${ }^{1}$, \\ Eva Lundin ${ }^{4}$, Alan A. Arslan ${ }^{2,3,5}$, Tomas Axelsson ${ }^{6}$, Asta Försti ${ }^{7,8}$, Göran Hallmans ${ }^{9}$, Kari Hemminki ${ }^{7,8}$, \\ Per Lenner ${ }^{10}$, Nirmal Roy ${ }^{3}$, Roy E. Shore ${ }^{3,11}$, Yu Chen ${ }^{1}$
}

1 Department of Population Health, New York University School of Medicine, New York, New York, United States of America, 2 New York University Cancer Institute, New York University School of Medicine, New York, New York, United States of America, 3 Department of Environmental Medicine, New York University School of Medicine, New York, New York, United States of America, 4 Department of Medical Biosciences, Pathology, Umeå University, Umeå, Sweden, 5 Department of Obstetrics and Gynecology, New York University School of Medicine, New York, New York, United States of America, 6 Molecular Medicine, Department of Medical Sciences, Uppsala University, Uppsala, Sweden, 7 Division of Molecular Genetic Epidemiology, German Cancer Research Center (DKFZ), Heidelberg, Germany, 8 Center for Primary Health Care Research, Clinical Research Center, Lund University, Malmö, Sweden, 9 Department of Public Health and Clinical Medicine/Nutritional Research, Umeå University, Umeå, Sweden, 10 Department of Oncology, Umeå University Hospital, Umeå, Sweden, 11 Radiation Effects Research Foundation, Hiroshima, Japan

\begin{abstract}
Sex hormones play a key role in the development of breast cancer. Certain polymorphic variants (SNPs and repeat polymorphisms) in hormone-related genes are associated with sex hormone levels. However, the relationship observed between these genetic variants and breast cancer risk has been inconsistent. We conducted a case-control study nested within two prospective cohorts to assess the relationship between specific genetic variants in hormone-related genes and breast cancer risk. In total, 1164 cases and 2111 individually-matched controls were included in the study. We did not observe an association between potential functional genetic polymorphisms in the estrogen pathway, SHBG rs6259, ESR1 rs2234693, CYP19 rs10046 and rs4775936, and UGT1A1 rs8175347, or the progesterone pathway, PGR rs1042838, with the risk of breast cancer. Our results suggest that these genetic variants do not have a strong effect on breast cancer risk.
\end{abstract}

Citation: Clendenen T, Zeleniuch-Jacquotte A, Wirgin I, Koenig KL, Afanasyeva Y, et al. (2013) Genetic Variants in Hormone-Related Genes and Risk of Breast Cancer. PLOS ONE 8(7): e69367. doi:10.1371/journal.pone.0069367

Editor: Erica Villa, University of Modena \& Reggio Emilia, Italy

Received February 5, 2013; Accepted June 7, 2013; Published July 23, 2013

Copyright: ( $) 2013$ Clendenen et al. This is an open-access article distributed under the terms of the Creative Commons Attribution License, which permits unrestricted use, distribution, and reproduction in any medium, provided the original author and source are credited.

Funding: This work was supported by National Cancer Institute grants R01 CA081212, R01 CA098661 and P30 CA016087 and Center grant ES000260 from the National Institute of Environmental Health Sciences. The funders had no role in study design, data collection and analysis, decision to publish, or preparation of the manuscript.

Competing Interests: The authors have declared that no competing interests exist.

*E-mail: tess.clendenen@nyumc.org

\section{Introduction}

Epidemiological evidence indicates a key role for sex hormones in breast cancer development. High circulating levels of estrogens and androgens have been consistently associated with increased breast cancer risk in postmenopausal women [1,2,3,4]. Established breast cancer risk factors, e.g., early age at menarche, nulliparity, late age at menopause, use of estrogen plus progestin hormone replacement therapy, and BMI among postmenopausal women, are thought to affect risk through modulation of sex hormones. Genetic variants in hormone-related genes have been shown to be associated with sex hormone levels $[5,6,7,8,9]$. However, associations observed between genetic variants in sex-hormone related genes and breast cancer risk have generally been inconsistent $[10,11]$, except for two single nucleotide polymorphisms (SNP) near the ESR1 gene (rs2046210 and rs12662670) that were significantly associated with risk in several genome wide association studies [12,13,14,15,16,17]. We assessed whether selected polymorphisms in genes that have been shown to be associated with sex hormone levels or hormone signaling are related to risk of breast cancer.

We selected several genes that encode for proteins involved in hormone signaling and metabolism: sex hormone-binding globulin
$(S H B G)$, which binds to, and reduces the biological availability of estrogens and androgens; the progesterone receptor $(P G R)$; the estrogen receptor alpha (ESR1); aromatase (CIP19), which converts androgens to estrogens; and UDP-glucuronosyltransferase 1Al (UGT1A1), which glucuronidates estrogens, thereby facilitating their excretion in urine. Candidate polymorphisms in these genes were selected based on their potential functional role (e.g., regulating endogenous hormone levels) and reported association with breast cancer risk at the time of initiation of our study. We selected polymorphisms that were associated with breast cancer risk in some, but not all, studies. The following polymorphisms were genotyped: $S H B G$ rs6259 [5,8,18,19,20]; PGR rs1042838 [11,20,21,22,23,24,25]; ESR1 rs2234693 $[20,26,27,28], \quad$ CYP19 $r 10046$ and rs4775936 $[5,7,20,29,30,31,32,33] ; \quad$ and UGT1A1 rs8175347 $[34,35,36,37,38,39]$.

\section{Methods}

\section{Ethics Statement}

The Institutional Review Board of New York University School of Medicine and the Regional Ethical Committee of the University 
of Umeå, Sweden, reviewed and approved this study. Written informed consent was obtained from all participants at enrollment.

\section{Study Subjects}

We conducted a case-control study nested within two prospective cohorts: the Northern Sweden Mammary Screening Cohort (NSMSG) [40] and the New York University Women's Health Study (NYUWHS). Details about the parent cohorts and breast cancer case ascertainment has been reported previously [3]. Briefly, the NYWHS cohort includes 14,274 healthy women (ages 34-65) enrolled between 1985-1991 at a mammography screening clinic in New York City and the NSMSC cohort includes over 28,000 healthy women (ages 40-69) enrolled between 1995-2006 during a population-based breast cancer screening program in Västerbotten County, Sweden. For the present study, only women self-described as Caucasian, African American, or Hispanic were included. All incident cases of invasive breast cancer, a total of 1164 cases, were included in our study (658 cases from NYUWHS and 506 cases from NSMSG). Two controls were individually matched to each case. Controls were selected at random from members of the same cohort who were alive and free of cancer at the time of diagnosis of the case, and who matched the case on age at enrollment ( \pm 6 months) and date of blood donation $( \pm 3$ months). NYUWHS cases and controls were also matched on menopausal status. Most of the cases from the NSMSC had at least one control matched on menopausal status (92\%). In total, 2111 controls were included in the study (1099 from NYUWHS and 1012 from NSMSC).

\section{Laboratory Methods}

For the NYUWHS participants, DNA was extracted from blood clots or cell precipitates (prepared by centrifugation of whole blood collected at blood donation) for $42 \%$ of participants. For the remainder of NYUWHS participants, DNA was extracted from serum. Samples were genotyped using the TaqMan ${ }^{\circledR}$ approach [41,42] with an ABI 7900 Real-Time PCR instrument (Applied Biosystems, Foster City, CA). The percent of successful genotyping calls was $\geq 98 \%$ for all genetic variants. Prior to the case-control study, a pilot study was conducted to examine genotype concordance across sample types (serum, clots, cell precipitates) for the NYUWHS study. For samples from the same participant ( $\mathrm{n}=50$ subjects with all three sample types plus $\mathrm{n}=68$ subjects with two sample types), genotype concordance was $\geq 99 \%$.

For the NSMSC participants, DNA was isolated from buffy coats. Genotyping was performed at the SNP Technology Platform at Uppsala University Hospital (www.genotyping.se) for five SNPs (rs4775936, rs10046, rs6259, rs2234693, rs1042838). Four of these SNPs (rs4775936, rs10046, rs6259, rs2234693) were assayed using the GenomeLab SNPStream 12plex-system (Beckman Coulter) and one (rs 1042838) using the FP-TDI system. UGT1A1 rs8175347 was assayed at the German Cancer Research Center in Heidelberg using fluorescent fragment analysis on an ABI PRISM 3100 Genetic analyzer with the GeneMapper software version 3.0 (Applied Biosystems). The percentage of samples with successful calls was $\geq 98 \%$ for all polymorphisms. We conducted a pilot study to assess genotype concordance across duplicate samples from NSMSC participants ( $\mathrm{n}=164$ duplicates). The concordance between samples from the same participant was $\geq 99 \%$ for all loci.

For both cohorts, each case and her individually-matched controls were analyzed as a set on the same 96-well plate. Quality control samples $(10 \%)$ were included on each plate and were interspersed throughout the plate with the case-control samples.
Laboratory personnel were blinded as to case-control status and the identity of the quality control samples.

\section{Statistical Methods}

We assessed deviation from Hardy-Weinberg equilibrium (HWE) in each cohort for each genetic variant with a chi-square test. Odds ratios and 95\% confidence intervals for breast cancer risk were estimated using the conditional logistic regression model, as appropriate for the matched study design. All models were adjusted for race/ethnicity (Caucasian, African American, or Hispanic) and through matching, were also adjusted for age at blood donation, duration of sample storage, and menopausal status. Multivariate-adjusted models included other known risk factors for breast cancer: family history of breast cancer (in a first degree relative), age at menarche, age at first birth/parity $(\leq 20$ years, 21-25 years, 26-30 years, $>30$ years, nulliparous), ever use of hormone replacement therapy, and body mass index (BMI). For covariates with missing data (age at menarche, age at first birth, use of hormone replacement therapy, and BMI), we performed multiple imputation of missing data for each cohort separately using a fully conditional specification model [43] including family history of breast cancer and case-control status along with the imputed variables. Each of the imputed variables had $<4 \%$ missing data. We also conducted a logistic regression including all of the estrogen-related variants simultaneously (all variants except PGR-12), where homozygous genotypes for the variant associated with higher estrogen was coded as one and the other genotypes were coded as zero and the sum of the scores was modeled as the independent variable (women with four or five variants were grouped because there were only 3 cases and 4 controls who had five high estrogen variants). Heterogeneity between cohorts was assessed by comparing models with cross-product terms (cohort $x$ genotype) to models excluding them using the likelihood ratio test. Analyses were also conducted separately for Caucasians $(n=1067$ cases, 1931 controls) and for estrogen receptor positive (ER+) breast cancer ( $\mathrm{n}=625$ cases, 1091 controls).

\section{Results}

Descriptive statistics for the cases and controls are shown in Table 1. The expected relationships between breast cancer and the traditional risk factors were observed. Among postmenopausal women, cases had a higher mean BMI than controls. Cases were more likely than controls to be nulliparous, to have ever used HRT, and to have a family history of breast cancer. Among parous women, average age at first birth was greater for cases than controls. The frequency of genotypes within controls did not deviate from Hardy-Weinberg Equilibrium by cohort (all p-values $>0.05$ ).

Table 2 shows that there were no statistically significant associations between the selected genetic variants in hormonerelated genes and risk of breast cancer in age- or multivariateadjusted models. For each genotype, variants are listed in order of expected increasing estrogen (or progesterone for the PGR SNP) exposure. There was no association with risk for individuals with multiple genotypes associated with high estrogen levels. Tests for heterogeneity by cohort were not significant. The odds ratios were not appreciably different in analyses restricted to Caucasians (data not shown). Tests for interaction between each genetic polymorphism and age at diagnosis were not significant. ORs were not significant and were generally similar in magnitude and direction for analyses restricted to ER+ breast cancer (data not shown), except that the OR estimates were no longer greater than one for the CYP19 rs10046 TT and rs4775936 AA genotypes. For SHBG 
Table 1. Distributions of demographic and lifestyle variables by breast cancer status.

\begin{tabular}{|c|c|c|c|}
\hline \multirow[t]{2}{*}{ Demographic and Lifestyle Variables } & \multirow{2}{*}{$\begin{array}{l}\text { Cases } \\
(\mathrm{N}=1164)\end{array}$} & \multirow{2}{*}{$\begin{array}{l}\text { Controls } \\
(\mathrm{N}=\mathbf{2 1 1 1})\end{array}$} & \multirow[t]{2}{*}{ p-value ${ }^{c}$} \\
\hline & & & \\
\hline Age (years) at enrollment, mean (SD) & $54.5(8.2)$ & $54.9(8.1)$ & Matched \\
\hline Age (years) at menarche, mean (SD) & $12.8(1.5)$ & $12.9(1.5)$ & 0.12 \\
\hline Unknown & 17 & 44 & \\
\hline Age (years) at diagnosis, mean (SD) & $61.9(8.5)$ & - & \\
\hline \multicolumn{4}{|l|}{ BMI $\left(\mathrm{kg} / \mathrm{cm}^{2}\right)$ at enrollment, mean (SD) } \\
\hline Pre-menopausal & $24.3(4.1)$ & $24.7(4.5)$ & 0.14 \\
\hline Post-menopausal & $26.0(4.4)$ & $25.3(4.1)$ & $<0.01$ \\
\hline Unknown & 29 & 48 & \\
\hline Menopausal status at enrollment, $n, \%$ & & & Matched \\
\hline Pre-menopausal & $442(38.0)$ & $745(35.3)$ & \\
\hline Post-menopausal & $722(62.0)$ & $1366(64.7)$ & \\
\hline Nulliparous at enrollment, n, \% & $261(23.2)$ & $367(17.8)$ & $<0.01$ \\
\hline Unknown & 38 & 54 & \\
\hline Age (years) at first full-term pregnancy, mean (SD) ${ }^{\mathrm{a}}$ & $25.4(4.8)$ & $24.8(4.6)$ & 0.01 \\
\hline Unknown & 22 & 34 & \\
\hline Race/ethnic background, n, \% & & & 0.47 \\
\hline Caucasian & 1067 (91.7) & $1931(91.5)$ & \\
\hline African American & $72(6.2)$ & $117(5.5)$ & \\
\hline Hispanic & $25(2.2)$ & $63(3.0)$ & \\
\hline Ever users of HRT, $n, \%^{b}$ & $393(35.6)$ & $648(31.7)$ & 0.03 \\
\hline Unknown & 60 & 66 & \\
\hline Family history of breast cancer, $n, \%$ & $218(18.7)$ & $306(14.5)$ & $<0.01$ \\
\hline \multicolumn{4}{|l|}{ Tumor Receptor Status } \\
\hline ER-positive & $625(72.7)$ & - & \\
\hline ER- negative & $235(27.3)$ & - & \\
\hline Unknown & 304 & & \\
\hline
\end{tabular}

${ }^{\mathrm{a}}$ For parous women only.

${ }^{b}$ HRT use during follow-up (for NYUWHS) or use history assessed at enrollment (NSMSC).

${ }^{c} p$-values were estimated using logistic regression conditional on matching sets. doi:10.1371/journal.pone.0069367.t001

rs6259, the OR was somewhat greater for ER+ tumors (OR for GG vs. GA/AA: $1.22,95 \%$ CI: $0.94-1.60)$ than for all tumors combined (for GG vs. GA/AA: 1.02, 95\% CI: 0.84-1.23), though the association was not significant.

\section{Discussion}

Our results are in agreement with those of large meta-analyses of hormone-related genetic variants and breast cancer risk (which included over 10,000 cases and 10,000 controls) that did not observe an association for SHBG rs6259, PGR rs 1042838, CYP19 rs10046 and rs4775936, or UGT1A1 rs8175347 variants $[32,44]$. Two meta-analyses (both with over 10,000 cases and 10,000 controls), observed a borderline inverse association for ESR1 rs2234693 (OR for C vs. T: 0.97, 95\% CI: 0.93-1.00 [32], $\mathrm{p}=0.055$ and OR for CC vs. TT: 0.92, 95\% CI: 0.86-0.99 [28]), which we did not observe in our study.

Three of the genetic variants we selected directly influence estrogen levels: CIP19 rs10046 and rs4775936 and UGT1A1 rs8175347. CYP19 encodes for the enzyme aromatase, which converts androgens to estrogens. The rs10046 $\mathrm{T}$ allele and the rs4775936 A allele have been shown to be associated with higher levels of circulating estrogen or estrogen to androgen ratios in several studies $[5,7,29,45]$, including our own [46]. The 7 base repeat allele of UGT1A1 rs8175347 is associated with lower transcriptional activity and may result in reduced glucuronidation of estrogens [34]. Circulating estrogen levels were higher among women with 7 base repeat alleles in our study [46] as in most other studies $[34,47]$. However, despite the relationship between these SNPs and estrogen levels, most studies, including our own, have not observed any association between these SNPs in CTP19 and UGT1A1 and breast cancer risk [32,48].

$S H B G$ rs6259 influences estrogen bioavailability and the A allele is associated with higher SHBG levels (suggesting lower estrogen bioavailability) in most $[5,8,18,19,49]$, but not all studies $[6,50]$. Consistent with most previous studies [32], we did not observe an association between rs6259 and risk of breast cancer.

$P G R$ rs 1042838 influences progesterone signaling and the $\mathrm{T}$ allele is in high linkage disequilibrium with the PROGINS allele, which reduces the $P G R$ transcript stability and may decrease the response to progesterone [23]. We did not observe an association between $P G R$ rs 1042838 and breast cancer risk, in agreement with nearly all previous studies [32]. 
Table 2. Associations between genetic variants in hormone-related genes and breast cancer risk in pre- and post-menopausal women.

\begin{tabular}{|c|c|c|c|}
\hline & \multirow{2}{*}{$n$ (Cases/Controls) } & \multirow{2}{*}{$\begin{array}{l}\text { Ethnicity-adjusted } \\
\text { ORs }(95 \% \mathrm{Cl})^{\mathrm{a}}\end{array}$} & \multirow{2}{*}{$\begin{array}{l}\text { Multivariate-adjusted } \\
\text { ORs }(95 \% \mathrm{Cl})^{\mathbf{b}}\end{array}$} \\
\hline & & & \\
\hline \multicolumn{4}{|l|}{ SHBG (rs6259) } \\
\hline AA & $15 / 28$ & 1.00 & 1.00 \\
\hline GA & 197/351 & $1.00(0.53-1.92)$ & $0.98(0.51-1.89)$ \\
\hline GG & $933 / 1655$ & $1.02(0.54-1.91)$ & $0.99(0.52-1.89)$ \\
\hline $\mathrm{p}$-trend & & 0.90 & 0.89 \\
\hline GG vs. GA/AA & & $1.01(0.84-1.22)$ & $1.02(0.84-1.23)$ \\
\hline \multicolumn{4}{|l|}{ PGR-12 (rs1042838) } \\
\hline$\pi T$ & $26 / 54$ & 1.00 & 1.00 \\
\hline GT & $288 / 523$ & $1.14(0.70-1.86)$ & $1.21(0.74-1.98)$ \\
\hline GG & $846 / 1516$ & $1.20(0.74-1.93)$ & $1.25(0.77-2.02)$ \\
\hline $\mathrm{p}$-trend & & 0.42 & 0.44 \\
\hline GG vs. GT/TT & & $1.06(0.90-1.25)$ & $1.05(0.89-1.24)$ \\
\hline \multicolumn{4}{|l|}{ ESR1 (rs2234693) } \\
\hline TT & $334 / 660$ & 1.00 & 1.00 \\
\hline СT & $585 / 1010$ & $1.14(0.96-1.35)$ & $1.13(0.95-1.34)$ \\
\hline CC & $244 / 436$ & $1.10(0.90-1.35)$ & $1.11(0.90-1.36)$ \\
\hline $\mathrm{p}$-trend & & 0.28 & 0.28 \\
\hline \multicolumn{4}{|l|}{ CYP19 3'UTR (rs10046) } \\
\hline CC & $306 / 549$ & 1.00 & 1.00 \\
\hline СT & $548 / 1032$ & $0.95(0.80-1.13)$ & $0.94(0.79-1.12)$ \\
\hline TT & $308 / 523$ & $1.07(0.87-1.31)$ & $1.04(0.85-1.28)$ \\
\hline $\mathrm{p}$-trend & & 0.53 & 0.71 \\
\hline \multicolumn{4}{|l|}{ CYP19 5'Flank (rs4775936) } \\
\hline GG & $361 / 654$ & 1.00 & 1.00 \\
\hline GA & $531 / 1011$ & $0.94(0.79-1.12)$ & $0.94(0.79-1.12)$ \\
\hline AA & $271 / 438$ & $1.13(0.92-1.39)$ & $1.10(0.89-1.36)$ \\
\hline $\mathrm{p}$-trend & & 0.33 & 0.46 \\
\hline \multicolumn{4}{|l|}{ UGT1A1 (rs8175347) } \\
\hline $6 / 6$ & $510 / 938$ & 1.00 & 1.00 \\
\hline $6 / 7$ & $478 / 846$ & $1.03(0.88-1.21)$ & $1.06(0.90-1.24)$ \\
\hline $7 / 7$ & $151 / 257$ & $1.06(0.84-1.34)$ & $1.06(0.84-1.34)$ \\
\hline $\mathrm{p}$-trend & & 0.60 & 0.51 \\
\hline \multicolumn{4}{|c|}{$\begin{array}{l}\text { Combined model for estrogen pathway } \\
\text { variants }{ }^{c}\end{array}$} \\
\hline 0 high E genotypes & $108 / 190$ & 1.00 & 1.00 \\
\hline 1 high E genotypes & $485 / 911$ & $0.93(0.72,1.21)$ & $0.93(0.71,1.21)$ \\
\hline 2 high E genotypes & $267 / 441$ & $1.07(0.81,1.41)$ & $1.08(0.82,1.44)$ \\
\hline 3 high E genotypes & $194 / 310$ & $1.12(0.83,1.50)$ & $1.11(0.82,1.50)$ \\
\hline 4-5 high E genotypes & $64 / 106$ & $1.06(0.71,1.57)$ & $1.00(0.67,1.50)$ \\
\hline $\mathrm{p}$-trend & & 0.15 & 0.21 \\
\hline
\end{tabular}

a Models were adjusted for ethnicity (Caucasian, African American, Hispanic) and through matching, were also adjusted for age at blood donation, duration of sample storage, and menopausal status.

${ }^{\mathrm{b}}$ Models were adjusted for ethnicity (Caucasian, African American, Hispanic), age at first birth/parity ( $\leq 20$ years, 21-25 years, 26-30 years, $>30$ years, nulliparous), age at menarche, family history of breast cancer, ever use of HRT, and BMI, and through matching, were also adjusted for age at blood donation, duration of sample storage, and menopausal status.

${ }^{c}$ For each genetic variant (except PGR-12 rs1042838), the genotype associated with higher estrogen exposure (see below) was assigned a value of 1 and other genotypes (homozygous and heterozygous for the lower estrogen exposure allele) were assigned 0 . A score was created by adding the values. Women with four or five high estrogen variables were grouped because there were too few women with five high estrogen variables to assess separately ( 3 cases/4 controls).

Notes: For each genotype, variants are listed in order of expected increasing estrogen (or progesterone for PGR-12) exposure:

SHBG (rs6259) A allele is associated with higher SHBG levels. SHBG binds to estrogens and reduces their bioavailability. $G$ allele $=$ higher estrogen exposure.

PGR-12 (rs1042838) T allele has been shown to reduce the $P G R$ transcript stability and the response to progesterone. G allele= higher progesterone exposure. 
Table 2 Cont.

ESR1 (rs2234693) C allele may be associated with increased ER $\alpha$ transcription. $C$ allele = possible higher exposure to estrogen signaling.

CYP19 3'UTR (rs 10046) T allele is associated with increased transcriptional activity of aromatase (converts androgens to estrogens). T allele $=$ higher estrogen exposure. CYP19 5'Flank (rs4775936) A allele is associated with increased transcriptional activity of aromatase (converts androgens to estrogens). A allele $=$ higher estrogen exposure.

UGT1A1 ( $r$ 8175347) 7 repeat allele is associated with reduced glucuronidation (and clearance) of estrogens. 7 repeat allele $=$ higher estrogen exposure.

doi:10.1371/journal.pone.0069367.t002

The function of the ESR1 rs2234693 SNP has not been clearly demonstrated, though the $\mathrm{C}$ allele produces a binding site for the B-myb transcription factor, which may result in an alternative form and/or altered expression of the estrogen receptor, and thus influence estrogen signaling [26]. Two large meta-analyses reported a moderate reduction in breast cancer risk associated with the $\mathrm{C}$ allele [28,32]. We did not observe any significant association for ESR1 rs2234693, consistent with the findings of most other studies (reviewed in [28,32]). We note that ESR1 rs2234693 is not in linkage disequilibrium with the SNPs near the ESR 1 gene that were associated with breast cancer risk in several genome wide association studies [12,13,14,15,16,17].

There is substantial evidence that higher levels of circulating estrogens are associated with an increased risk of breast cancer in postmenopausal women. A pooled analysis of nine prospective epidemiologic studies found that for a doubling in estradiol levels, there was about a $29 \%$ increase in risk [51]. The genetic polymorphisms we examined were associated with an increase in estrone levels ranging from $6-28 \%$ in our study, which is consistent with observations from other studies for estradiol (range $\sim 5-60 \%$ ) $[5,7,29,34,45,47]$. Thus, it is unlikely that the effect of any of these SNPs alone on estrogen levels is large enough to have a measurable effect on breast cancer risk and may explain why

\section{References}

1. Key T, Appleby P, Barnes I, Reeves G (2002) Endogenous sex hormones and breast cancer in postmenopausal women: reanalysis of nine prospective studies. J Natl Cancer Inst 94: 606-616.

2. Missmer SA, Eliassen AH, Barbieri RL, Hankinson SE (2004) Endogenous estrogen, androgen, and progesterone concentrations and breast cancer risk among postmenopausal women. J Natl Cancer Inst 96: 1856-1865.

3. Lukanova A, Lundin E, Micheli A, Arslan AA, Ferrari P, et al. (2004) Circulating levels of sex steroid hormones and risk of endometrial cancer in postmenopausal women. Int J Cancer 108: 425-432.

4. Kaaks R, Rinaldi S, Key TJ, Berrino F, Peeters PH, et al. (2005) Postmenopausal serum androgens, oestrogens and breast cancer risk: the European prospective investigation into cancer and nutrition. Endocr Relat Cancer 12: 1071-1082.

5. Dunning AM, Dowsett M, Healey CS, Tee L, Luben RN, et al. (2004) Polymorphisms associated with circulating sex hormone levels in postmenopausal women. J Natl Cancer Inst 96: 936-945.

6. Haiman C, Riley S, Freedman M, Setiawan V, Conti D, et al. (2005) Common genetic variation in the sex steroid hormone-binding globulin (SHBG) gene and circulating shbg levels among postmenopausal women: the Multiethnic Cohort. J Clin Endocrinol Metab 90: 2198-2204.

7. Beckmann L, Husing A, Setiawan VW, Amiano P, Clavel-Chapelon F, et al. (2011) Comprehensive analysis of hormone and genetic variation in 36 genes related to steroid hormone metabolism in pre- and postmenopausal women from the breast and prostate cancer cohort consortium (BPC3). J Clin Endocrinol Metab 96: E360-367.

8. Thompson DJ, Healey CS, Baynes C, Kalmyrzaev B, Ahmed S, et al. (2008) Identification of common variants in the SHBG gene affecting sex hormonebinding globulin levels and breast cancer risk in postmenopausal women. Cancer Epidemiol Biomarkers Prev 17: 3490-3498.

9. Johnson N, Walker K, Gibson LJ, Orr N, Folkerd E, et al. (2012) CYP3A Variation, Premenopausal Estrone Levels, and Breast Cancer Risk. J Natl Cancer Inst 104: 657-669.

10. Mavaddat N, Antoniou AC, Easton DF, Garcia-Closas M (2010) Genetic susceptibility to breast cancer. Mol Oncol 4: 174-191. most studies, including our own, did not find an association with risk.

The ages at enrollment into the parent cohorts were 34-65 for the NYUWHS and 40-69 for the NSMSC. While generalizability of our results to other populations requires caution, it is unlikely that the relationship between these common genetic variants and breast cancer risk is limited to women in the same age range as in our study.

In agreement with the largest meta-analyses of epidemiological studies to date, we did not observe an association for $S H B G$ rs6259, PGR rs1042838, ESR1 rs2234693, CYP19 rs10046 and rs4775936, and UGT1A1 rs8175347 and breast cancer risk. The effects of other genetic variants in these or other hormone-related genes, individually or in combination, may have an effect on breast cancer risk. In conclusion, our study provides supportive evidence that these genetic variants in hormone-related genes are not likely to have a strong effect on breast cancer risk.

\section{Author Contributions}

Conceived and designed the experiments: AZJ KLK RES. Performed the experiments: IW NR TA. Analyzed the data: TVC AZJ KLK YA YG. Contributed reagents/materials/analysis tools: IW NR TA. Wrote the paper: TVC AZJ KLK YC. Interpretation of the data and revision of the manuscript: TVC AZJ IW KLK YA EL AAA AF GH KH PL RES YG.

11. (2006) Commonly studied single-nucleotide polymorphisms and breast cancer: results from the Breast Cancer Association Consortium. J Natl Cancer Inst 98: $1382-1396$.

12. Zheng W, Long J, Gao YT, Li C, Zheng Y, et al. (2009) Genome-wide association study identifies a new breast cancer susceptibility locus at 6 q25.1. Nat Genet 41: 324-328.

13. Antoniou AC, Kartsonaki C, Sinilnikova OM, Soucy P, McGuffog L, et al. (2011) Common alleles at 6q25.1 and 1p11.2 are associated with breast cancer risk for BRCA1 and BRCA2 mutation carriers. Human molecular genetics 20: 3304-3321.

14. Cai Q, Wen W, Qu S, Li G, Egan KM, et al. (2011) Replication and functional genomic analyses of the breast cancer susceptibility locus at 6q25.1 generalize its importance in women of chinese, Japanese, and European ancestry. Cancer research 71: 1344-1355.

15. Stevens KN, Vachon CM, Lee AM, Slager S, Lesnick T, et al. (2011) Common breast cancer susceptibility loci are associated with triple-negative breast cancer. Cancer research 71: 6240-6249.

16. Hein R, Maranian M, Hopper JL, Kapuscinski MK, Southey MC, et al. (2012) Comparison of 6q25 breast cancer hits from Asian and European Genome Wide Association Studies in the Breast Cancer Association Consortium (BCAC). PLoS One 7: e42380.

17. Turnbull C, Ahmed S, Morrison J, Pernet D, Renwick A, et al. (2010) Genomewide association study identifies five new breast cancer susceptibility loci. Nat Genet 42: 504-507.

18. Cui Y, Shu XO, Cai Q, Jin F, Cheng JR, et al. (2005) Association of breast cancer risk with a common functional polymorphism (Asp327Asn) in the sex hormone-binding globulin gene. Cancer Epidemiol Biomarkers Prev 14: 10961101.

19. Ding E, Song Y, Manson J, Hunter D, Lee C, et al. (2009) Sex hormone-binding globulin and risk of type 2 diabetes in women and men. N Engl J Med 361: 1152-1163.

20. Canzian F, Cox DG, Setiawan VW, Stram DO, Ziegler RG, et al (2010) Comprehensive analysis of common genetic variation in 61 genes related to steroid hormone and insulin-like growth factor-I metabolism and breast cancer risk in the NCI breast and prostate cancer cohort consortium. Hum Mol Genet 19: 3873-3884. 
21. Pooley KA, Healey CS, Smith PL, Pharoah PD, Thompson D, et al. (2006) Association of the progesterone receptor gene with breast cancer risk: a singlenucleotide polymorphism tagging approach. Cancer Epidemiol Biomarkers Prev 15: 675-682.

22. De Vivo I, Hankinson SE, Colditz GA, Hunter DJ (2004) The progesterone receptor Val660->Leu polymorphism and breast cancer risk. Breast Cancer Res 6: R636-639.

23. Romano A, Delvoux B, Fischer DC, Groothuis P (2007) The PROGINS polymorphism of the human progesterone receptor diminishes the response to progesterone. J Mol Endocrinol 38: 331-350.

24. Johnatty SE, Spurdle AB, Beesley J, Chen X, Hopper JL, et al. (2008) Progesterone receptor polymorphisms and risk of breast cancer: results from two Australian breast cancer studies. Breast Cancer Res Treat 109: 91-99.

25. Gaudet MM, Milne RL, Cox A, Camp NJ, Goode EL, et al. (2009) Five polymorphisms and breast cancer risk: results from the Breast Cancer Association Consortium. Cancer Epidemiol Biomarkers Prev 18: 1610-1616.

26. Herrington DM, Howard TD, Brosnihan KB, McDonnell DP, Li X, et al. (2002) Common estrogen receptor polymorphism augments effects of hormone replacement therapy on E-selectin but not C-reactive protein. Circulation 105: 1879-1882.

27. Sakoda LC, Blackston GR, Doherty JA, Ray RM, Lin MG, et al. (2011) Selected estrogen receptor 1 and androgen receptor gene polymorphisms in relation to risk of breast cancer and fibrocystic breast conditions among Chinese women. Cancer Epidemiol 35: 48-55.

28. Li N, Dong J, Hu Z, Shen H, Dai M (2010) Potentially functional polymorphisms in ESR 1 and breast cancer risk: a meta-analysis. Breast Cancer Res Treat 121: 177-184.

29. Haiman C, Dossus L, Setiawan V, Stram D, Dunning A, et al. (2007) Genetic variation at the CYP19A1 locus predicts circulating estrogen levels but not breast cancer risk in postmenopausal women. Cancer Res 67: 1893-1897.

30. Chen C, Sakoda LC, Doherty JA, Loomis MM, Fish S, et al. (2008) Genetic variation in CYP19A1 and risk of breast cancer and fibrocystic breast conditions among women in Shanghai, China. Cancer Epidemiol Biomarkers Prev 17: 3457-3466.

31. Olson JE, Ingle JN, Ma CX, Pelleymounter LL, Schaid DJ, et al. (2007) A comprehensive examination of CYP19 variation and risk of breast cancer using two haplotype-tagging approaches. Breast Cancer Res Treat 102: 237-247.

32. Zhang B, Beeghly-Fadiel A, Long J, Zheng W (2011) Genetic variants associated with breast-cancer risk: comprehensive research synopsis, meta-analysis, and epidemiological evidence. Lancet Oncol 12: 477-488.

33. Kristensen VN, Harada N, Yoshimura N, Haraldsen E, Lonning PE, et al. (2000) Genetic variants of CYP19 (aromatase) and breast cancer risk. Oncogene 19: 1329-1333.

34. Guillemette C, De Vivo I, Hankinson SE, Haiman CA, Spiegelman D, et al. (2001) Association of genetic polymorphisms in UGT1A1 and breast cancer and plasma hormone levels. Cancer Epidemiol Biomark Prev 10: 711-714.

35. Adegoke OJ, Shu XO, Gao Y'T, Cai Q, Breyer J, et al. (2004) Genetic polymorphisms in uridine diphospho-glucuronosyltransferase 1A1 (UGT1A1) and risk of breast cancer. Breast Cancer Res Treat 85: 239-245.
36. Cheng TC, Chen ST, Huang CS, Fu YP, Yu JC, et al. (2005) Breast cancer risk associated with genotype polymorphism of the catechol estrogen-metabolizing genes: a multigenic study on cancer susceptibility. Int J Cancer 113: 345-353.

37. Huo D, Kim HJ, Adebamowo CA, Ogundiran TO, Akang EE, et al. (2008) Genetic polymorphisms in uridine diphospho-glucuronosyltransferase 1A1 and breast cancer risk in Africans. Breast Cancer Res Treat 110: 367-376.

38. Tsezou A, Tzetis M, Giannatou E, Gennatas C, Pampanos A, et al. (2007) Genetic polymorphisms in the UGT1A1 gene and breast cancer risk in Greek women. Genet Test 11: 303-306.

39. Yao L, Qiu LX, Yu L, Yang Z, Yu XJ, et al. (2010) The association between TA-repeat polymorphism in the promoter region of UGT1A1 and breast cancer risk: a meta-analysis. Breast Cancer Res Treat 122: 879-882.

40. Hulten K, Van Kappel AL, Winkvist A, Kaaks R, Hallmans G, et al. (2001) Carotenoids, alpha-tocopherols, and retinol in plasma and breast cancer risk in northern Sweden. Cancer Causes Control 12: 529-537.

41. Hui L, DelMonte T, Ranade K (2008) Genotyping using the TaqMan assay. Curr Protoc Hum Genet Chapter 2: Unit 2.10.

42. Shen G, Luo A, Wang Q (2006) High-throughput single-nucleotide polymorphisms genotyping: TaqMan assay and pyrosequencing assay. Methods $\mathrm{Mol}$ Med 128: 209-224.

43. van Buuren S (2007) Multiple imputation of discrete and continuous data by fully conditional specification. Stat Methods Med Res 16: 219-242.

44. Zhou JY, Shi R, Yu HL, Zheng WL, Ma WL (2012) Association between SHBG Asp327Asn (rs6259) polymorphism and breast cancer risk: a meta-analysis of 10,454 cases and 13,111 controls. Molecular biology reports 39: 8307-8314.

45. Paynter RA, Hankinson SE, Colditz GA, Kraft P, Hunter DJ, et al. (2005) CYP19 (aromatase) haplotypes and endometrial cancer risk.[Erratum appears in Int J Cancer. 2008 Mar 15;122(6): 1443]. Int J Cancer 116: 267-274.

46. Lundin E, Wirgin I, Lukanova A, Afanasyeva Y, Krogh V, et al. (2012) Selected polymorphisms in sex hormone-related genes, circulating sex hormones and risk of endometrial cancer. Cancer Epidemiol 36: 445-452.

47. Sparks R, Ulrich CM, Bigler J, Tworoger SS, Yasui Y, et al. (2004) UDPglucuronyltransferase and sulfotransferase polymorphisms, sex hormone concentrations, and tumor receptor status in breast cancer patients. Breast Cancer Res 6: R488-R498.

48. Pineda B, Garcia-Perez MA, Cano A, Lluch A, Eroles P (2013) Associations between aromatase CYP19 rs10046 polymorphism and breast cancer risk: from a case-control to a meta-analysis of 20,098 subjects. PLoS One 8: e53902.

49. Riancho JA, Valero C, Zarrabeitia MT, Garcia-Unzueta MT, Amado JA, et al. (2008) Genetic polymorphisms are associated with serum levels of sex hormone binding globulin in postmenopausal women. BMC Med Genet 9: 112.

50. Napoli N, Varadharajan A, Rini GB, Del Fiacco R, Yarramaneni J, et al. (2009) Effects of polymorphisms of the sex hormone-binding globulin (SHBG) gene on free estradiol and bone mineral density. Bone 45: 1169-1174.

51. Key TJ (2011) Endogenous oestrogens and breast cancer risk in premenopausal and postmenopausal women. Steroids 76: 812-815. 